\title{
Evaluation of Patients with Lung Cancer Treated with Epidermal Growth Factor Receptor-Tyrosine Kinase Inhibitor
}

\author{
Laksmi Wulandari $^{1}$ Anna Febriani ${ }^{1}$ Farah Fatmawati ${ }^{1}$ Gatot Soegiarto ${ }^{2}$ \\ ${ }^{1}$ Department of Pulmonology and Respiratory Medicine, \\ Medical Faculty, Universitas Airlangga, Surabaya, Indonesia \\ 2Department of Internal Medicine, Medical Faculty, \\ Universitas Airlangga, Surabaya, Indonesia \\ Address for correspondence Laksmi Wulandari, MD, PhD, \\ Pulmonologist, Jl. Ketintang Wiyata 2/25, Surabaya 60231, Indonesia \\ (e-mail: laksmigts@yahoo.co.id).
}

Asian J Oncol 2018;4:48-53

\begin{abstract}
Epidermal growth factor receptor-tyrosine kinase inhibitor (EGFR-TKI) is currently the standard therapy for EGFR-mutated non-small cell lung cancer (NSCLC). Gefitinib is the first EGFR-TKI marketed in Indonesia and has been used since 2012 in Dr. Soetomo General Hospital, a tertiary hospital in Surabaya, East Java, Indonesia. Although the drug had shown some positive results, the overall treatment outcome for Indonesian patients has not been reported yet. The aim of the study is to evaluate the progression-free survival (PFS), overall survival (OS), and subjective response of gefitinib as firstline treatment in advanced EGFR-mutated NSCLC patients in Dr. Soetomo General Hospital. This retrospective study includes all eligible patients treated from 2013 to 2016. Demographic data, performance status, tumor histopathologic types, treatment response, and adverse effects (AEs) during the treatment course were collected from patient's medical records. Objective response was based on RECIST 1.1. Quality of life was assessed using Eq. 5D questionnaire. From evaluable data of 63 patients, median PFS

Keywords

- epidermal growth factor receptor

- lung cancer

- tyrosine kinase inhibitor was 8.3 months ( $95 \%$ confidence interval [Cl: 6.50-10.2) with median OS of 16 months (95\% Cl: 11.9-20.2). Eq. 5D scores were decreased in 21 (33.3\%) patients, stable in 22 (34.9\%), and increased in 20 (31.7\%). The most common side effects were itchy skin rash in 52 (82\%) patients and diarrhea in 29 (46\%). Gefitinib as first-line therapy provides a good objective response and is generally well tolerated in patients with EGFR-mutated NSCLC in Dr. Soetomo General Hospital.
\end{abstract}

\section{Introduction}

Lung cancer is the leading cause of cancer-related mortality in men and women in the United States 1,2 with the incidence of 224,390 cases in 2016 or approximately $13 \%$ of all cancer cases, which will eventually lead to 158,080 deaths. ${ }^{3}$ Based on Indonesian Ministry of Health's data from Dharmais National Cancer Hospital Jakarta in 2013, lung cancer is the third most common cause of cancer death, after breast and cervical cancer, with a total of 173 cases ( $7 \%$ of all cancer cases) and 65 deaths (12\% of all cancer death). ${ }^{4}$ The incidence of lung cancer is strongly related to smoking history. About $10 \%$ of chronic smokers will eventually be diagnosed as having lung cancer. ${ }^{1}$ Most of lung cancer patients come to the hospital in late stage with 1 - and 5 -year survival rate of only $26 \%$ and $4 \%$, respectively. ${ }^{3}$

The World Health Organization (WHO) divided lung cancer into two main classes based on biology, therapy, and prognosis: non-small cell lung cancer (NSCLC) and small cell lung cancer (SCLC). More than $85 \%$ of all lung cancers are NSCLC, consisting of nonsquamous carcinoma (adenocarcinoma, large cell carcinoma, and other cell types) and squamous cell carcinoma (epidermoid carcinoma). Adenocarcinoma is the most common type of lung cancer
DOI https://doi.org/ 10.1055/s-0038-1676872 ISSN 2454-6798.
License terms

(ㅇ) (1) $\ominus \circledast$ 
in the United States and the most frequent type of lung malignancy in nonsmoking patients in the world., ${ }^{2,5-8}$

Surgery, radiotherapy, and chemotherapy are the three modalities commonly used as therapy in NSCLC patients, which could be given alone or in combination depending on the disease stage and patient's performance status. Chemotherapy with platinum-based regimens shows a decent result in patients with advanced stage who had good performance status (PS), ${ }^{2,9}$ which can extend the life survival to approximately 7 to 8 months, reduce the symptoms, and slightly improve the quality of life (QoL). However, the toxicity is often a major disadvantage. Therefore, several researches have been performed to develop new drugs with a high therapeutic index and low toxicity that can improve the outcome of cancer patients. Recently, a new molecule targeting the signal transduction of epidermal growth factor receptor (EGFR) was found. These substances could inhibit the growth of cancer cells, with minimal effects on normal cell function. The pharmacokinetic and pharmacodynamic characteristics are favorable, and the toxic effects are quite low. ${ }^{10}$

Gefitinib is one of the first epidermal growth factor receptor-tyrosine kinase inhibitor (EGFR-TKI) marketed in Indonesia. There have been four phase III randomized trials in East Asia since August 2010 comparing gefitinib with platinum-based chemotherapy as first-line therapy in advanced stage of NSCLC patients. Gefitinib is associated with longer progression-free survival (PFS), higher objective response rates, more acceptable toxicity profiles, and better QoL compared with standard chemotherapy. ${ }^{11-15}$ In July 2009, The European Medicines Agency granted marketing authorization for gefitinib as therapy for locally advanced or metastatic EGFR-mutated NSCLC. EGFR-TKI, such as gefitinib, currently represents the best first-line therapeutic option for patients with EGFR-mutated NSCLC, which were commonly found in women, nonsmokers, adenocarcinoma histology, and Asian ethnicity. ${ }^{16-18}$

The use of gefitinib in Dr. Soetomo General Hospital, Surabaya, Indonesia, began in 2012 through health insurance covered by the government. Our group found that gefitinib showed a significant improvement of subjective responses and an increase in partial objective response in most patients after 2 months of therapy. These data indicated the effectiveness of gefitinib as first-line therapy in EGFR-mutated NSCLC patients. ${ }^{10,19}$ Based on previous studies, we determine the PFS, overall survival (OS), objective response, side effects, and QoL of all patients who had received gefitinib as first-line therapy in Dr. Soetomo General Hospital.

\section{Methods}

This was an analytic observational study with a retrospective cohort design. The population of the study was patients diagnosed with NSCLC and treated in Oncology Outpatient Clinic (Poli Onkologi Satu Atap [POSA]) Dr. Soetomo General Hospital. All data of NSCLC patients with positive EGFR mutations who had received gefitinib as first-line therapy from January 2013 to June 2015 that met the inclusion and exclusion criteria were collected.
The inclusion criteria were as follows: (1) patients diagnosed with NSCLC based on the histopathology results, (2) NSCLC adenocarcinoma and/or nonadenocarcinoma with positive EGFR mutation, (3) disease stages IIIB and IV, (4) aged 16 to 70 years, (5) patients who received gefitinib as first-line therapy, and (6) patients who had at least two evaluations performed with RECIST 1.1 during the whole study period from January 2013 to July 2016. The exclusion criteria were all patients with incomplete outcome data on medical record. We collected secondary data including history taking, physical examination, and laboratory and imaging data before and after gefitinib therapy, including computed tomographic (CT) scan of the thorax at baseline and at every 2 months evaluation.

We followed our patients until disease progression or until the end of study period on July 2016 through medical records data. The treatment efficacy was assessed by RECIST 1.1 criteria based on thorax CT scan data and/ or physician's clinical judgment, and those data were used to calculate the PFS and OS. The QoL were evaluated using WHO Eq. 5D questionnaires, whereas safety was assessed by evaluation of the recorded side effects based on clinical signs and symptoms and laboratory results. Toxicities included dermatology (rash, pruritus, and paronychia), gastrointestinal tract (GIT) (diarrhea), lung (interstitial lung disease [ILD]), and hepatotoxicity. The study protocol was approved by the ethics committee of Dr. Soetomo General Hospital (No: 453/Panke/I/2015) and registered at clinicaltrial.gov (NCT02755337).

Descriptive statistical analysis: mean or median calculation, proportion of PFS and OS, Eq. 5D questionnaire scores, and frequency of side effects were performed.

\section{Results}

Out of 101 outpatients, 36 patients were excluded due to various reasons; for example, 9 patients lost to follow-up, 16 had no CT scan evaluation, 7 received chemotherapy previously, 2 did not take gefitinib regularly for several months, 1 patient had long-time interval between baseline and evaluation CT scan (16 months), and 1 was with incomplete medical record data. Finally, 63 patients were available for evaluation.

- Table 1 shows the characteristics of 63 patients, consisted of 40 (63.5\%) female patients and 23 (36.5\%) male patients. Total $44(69.8 \%)$ patients were nonsmokers and 19 (30.2\%) were smokers. Initial PS score was 1 in 51 patients (81.0\%), 2 in 10 patients (15.9\%), and 3 in 2 patients (3.1\%). Based on the cancer stage, 5 (7.9\%) patients were in stage IIIB and 58 (92.1\%) were in stage IV. Total 60 (95.2\%) patients had adenocarcinoma, 2 (3.2\%) had adenosquamous, and 1 (1.6\%) patient had squamous cell carcinoma type. Forty-one (65.1\%) patients had exon 19 mutations, 21 (33.3\%) had exon 21 L858R mutations, and 1 (1.6\%) patient had exon 21 L861Q mutation.

Overall, gefitinib showed a good objective response rate, as can be seen in one of our patients (SRU), as a representative of 
Table 1 Characteristics of 63 study patients $(n=63)$

\begin{tabular}{|c|c|}
\hline Characteristic & $n(\%)$ \\
\hline \multicolumn{2}{|l|}{ Age $(y)$} \\
\hline Median & 56 \\
\hline Range & $33-70$ \\
\hline \multicolumn{2}{|l|}{ Sex } \\
\hline Male & $23(36.5)$ \\
\hline Female & $40(63.5)$ \\
\hline \multicolumn{2}{|l|}{ Smoking history } \\
\hline Never smoked & $44(69.8)$ \\
\hline Adenocarcinoma & 43 \\
\hline Squamous & 0 \\
\hline Adenosquamous & 1 \\
\hline Smoker & $19(30.2)$ \\
\hline Adenocarcinoma & 17 \\
\hline Squamous & 1 \\
\hline Adenosquamous & 1 \\
\hline \multicolumn{2}{|c|}{ WHO performance status } \\
\hline 0 & $0(0)$ \\
\hline 1 & $51(81)$ \\
\hline 2 & 10 (15.9) \\
\hline 3 & $2(3.1)$ \\
\hline \multicolumn{2}{|c|}{ Histologic feature of the tumor } \\
\hline Adenocarcinoma & $60(95.2)$ \\
\hline Squamous & $1(1.6)$ \\
\hline Adenosquamous & $2(3.2)$ \\
\hline \multicolumn{2}{|c|}{ Disease stage at diagnosis } \\
\hline IIIB & $5(7.9)$ \\
\hline IV & $58(92.1)$ \\
\hline \multicolumn{2}{|l|}{ EGFR mutation type } \\
\hline Exon 19 & $41(65.1)$ \\
\hline Exon 21L858R & $21(33.3)$ \\
\hline Exon 21L861Q & $1(1.6)$ \\
\hline
\end{tabular}

Abbreviations: EGFR, epidermal growth factor receptor; WHO, World Health Organization.

patients with clinical response (- Fig. 1). Kaplan-Meier curve was used to express PFS and OS estimation. We found that PFS was 8.3 months (95\% confidence interval [CI]: 6.50-10.2) (-Fig. 2) and OS was 16 months (95\% CI: 11.9-20.2) (Fig. 3).

QoL was assessed after 2 months of gefitinib therapy using the Eq. 5D questionnaire, which is a semisubjective response measurement. A decrease in Eq. 5D values shows QoL improvements, whereas an increase in Eq. 5D denotes a worsening QoL. The Eq. 5D scores calculated from 63 patients showed that 21 (33.3\%) patients experienced an improvement in the QoL, 22 (34.9\%) had no changes (stable), whereas the other 20 (31.7\%) patients had a decreased QoL (-Table 2).
The most common side effects in patients receiving gefitinib were itchy rash on the skin, face, or head, which reported by $52(82.5 \%)$ patients. Other recorded complaints included diarrhea in 29 (46.0\%) patients, nausea and vomiting in 13 (20.6\%), acne in 11 (17.5\%), paronychia in $9(14.3 \%)$, alopecia in $5(7.9 \%)$, dry skin in $3(4.8 \%)$, mucositis in $3(4.8 \%)$, tingling sensation in $2(3.2 \%)$, carbuncle in 2 (3.2\%), hearing loss in 1 (1.6\%) patient, increase alanine aminotransferase (ALT) and aspartate aminotransferase (AST) in $1(1.6 \%)$, and melena in $1(1.6 \%)$. All side effects in patients were mild, and none of side effects led to drug discontinuation (-Table 3 ). 

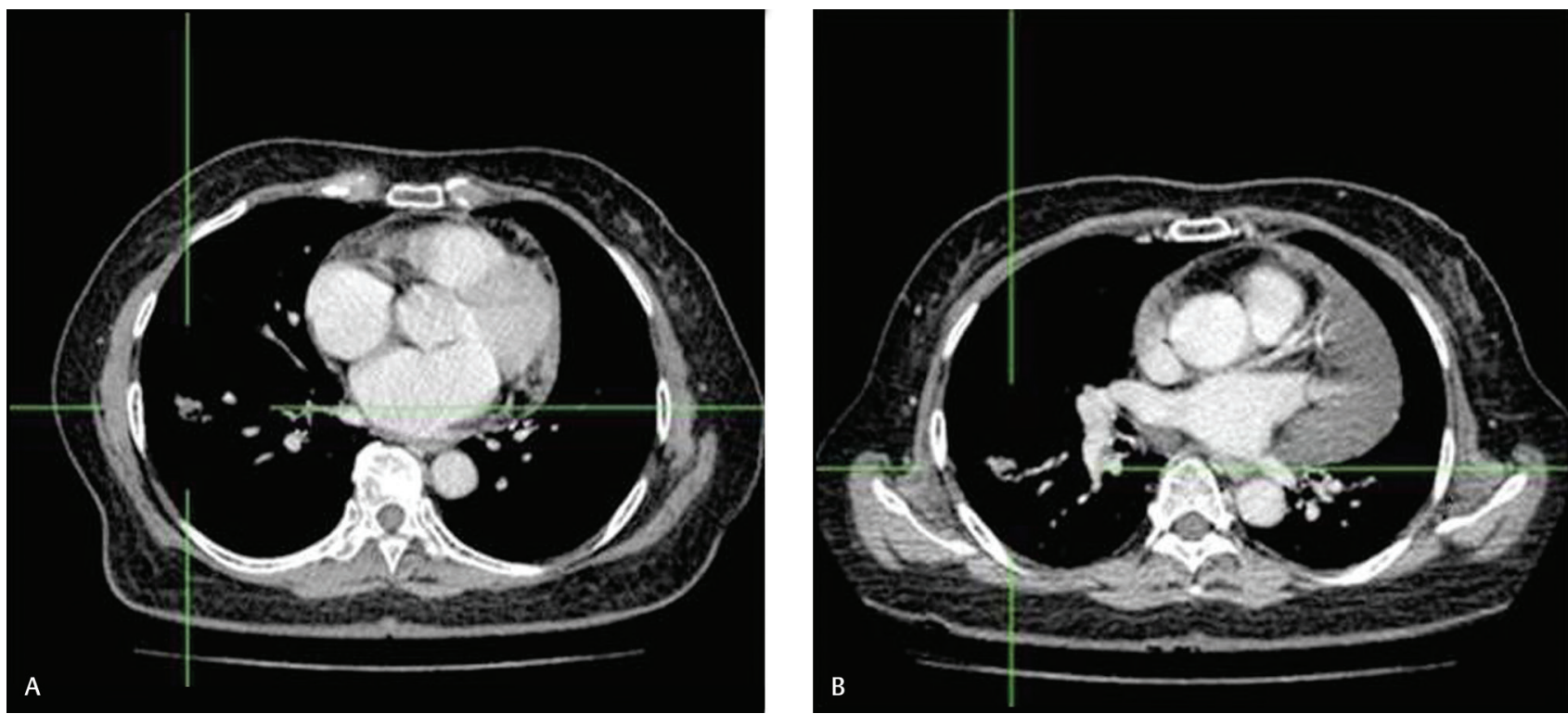

Fig. 1 Objective response to gefitinib in one of study patients. (A) Computed tomographic scan image of one of our study patients just before treatment. Irregular mass was seen on the right lung hilar region $(1.6 \mathrm{~cm} \times 1.1 \mathrm{~cm} \times 1 \mathrm{~cm})$, and there was severe pericardial effusions. (B) Computed tomographic scan evaluation 2 months after starting gefitinib showed that the mass had shrunk considerably $(1.6 \mathrm{~cm} \times 0.7 \mathrm{~cm} \times 1.1 \mathrm{~cm})$, pericardial effusion diminished significantly, and there was no lymph node enlargement.



Fig. 2 Progression-free survival of study patients. Kaplan-Meier curve of progression-free survival from the start of the gefitinib $(n=63)$. The median progression-free survival was 8.3 months (95\% confidence interval: 6.50-10.2).

Table 2 QoL evaluation using Eq. 5D questionnaire

\begin{tabular}{|l|l|}
\hline Eq. 5D level & $n(\%)$ \\
\hline Increasing Eq. 5D level (decreased QoL) & $20(31.7)$ \\
\hline Stable Eq. 5D level (stable QoL) & $22(34.9)$ \\
\hline Decreasing Eq. 5D level (improved QoL) & $21(33.3)$ \\
\hline
\end{tabular}

Abbreviation: QoL, quality of life.

\section{Discussion}

The median age of our patients was 56 years, almost the same as the median age of patients in the IPASS study (57 years). ${ }^{9}$ The majority of our patients were female, nonsmoker, had adenocarcinoma type of lung cancer, stage IV disease, and EGFR mutation of exon 19. The results were similar to those

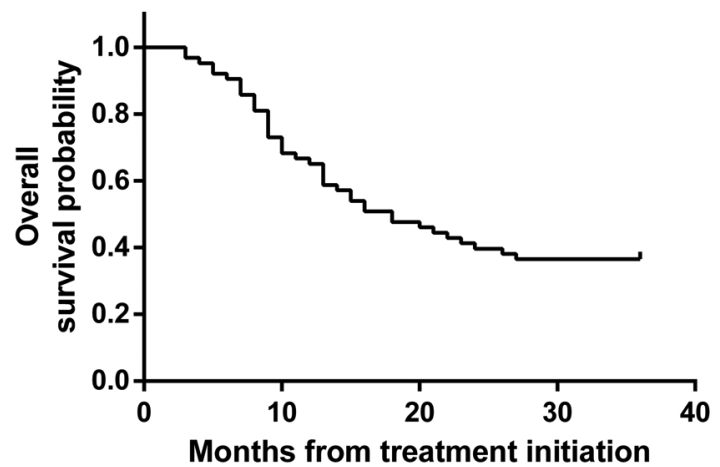

Fig. 3 Overall survival of study patients. Kaplan-Meier curve of overall survival from the start of the gefitinib $(n=63)$. The median overall survival was 16 months (95\% confidence interval: 11.9-20.2).

in the IPASS and WJTOG3405 studies.9.14 Most patients had initial PS score 1, comparable to the patients in IPASS study. However, in WJTOG3405 study, most patients had initial PS score 0 . This difference could be due to the different treatment seeking patterns between studies in which most of our patients came to the hospital after symptoms appeared and were at more advanced stage of the disease.

All patients who had received gefitinib were NSCLC patients with the same positive EGFR mutation as in WJTOG3405 and NEJ002..$^{12,14,15}$ This result was in accordance with the previous studies, in which EGFR mutations were more common in patients who never smoked, those who were female, and those who had adenocarcinoma type of lung cancer. In the IPASS study, there were several patients with EGFR mutations in exon 20, but also other mutations 
Table 3 Recorded side effects

\begin{tabular}{|l|l|}
\hline Side effect & All grade; $\boldsymbol{n}$ (\%) \\
\hline Itchy skin rash & $52(82.5)$ \\
\hline Diarrhea & $29(46.0)$ \\
\hline Nausea and vomiting & $13(20.6)$ \\
\hline Acne & $11(17.5)$ \\
\hline Paronychia & $9(14.3)$ \\
\hline Alopecia & $5(7.9)$ \\
\hline Dry skin & $3(4.8)$ \\
\hline Mucositis & $3(4.8)$ \\
\hline Neuropathy (tingling sensation) & $2(3.2)$ \\
\hline Carbuncle & $2(3.2)$ \\
\hline Hearing loss & $1(1.6)$ \\
\hline Increased ALT and AST & $1(1.6)$ \\
\hline Melena & $1(1.6)$ \\
\hline
\end{tabular}

Abbreviations: ALT, alanine transaminase; AST, aspartate transaminase.

and multiple mutations, whereas in our study, there were only EGFR mutations in exons 19 and 21, because at that time the tests performed in Indonesia could only detect EGFR mutations in exons 19 and 21.

PFS was calculated from the time patients received gefitinib until the time they showed the earliest signs of disease progression (by RECIST 1.1 evaluation) or until the time of death due to any reasons. This is similar to the IPASS study, ${ }^{9}$ in which some patients died before the last RECIST evaluation demonstrated progression of the disease. OS was calculated from the time patients received gefitinib until the time of death due to any reasons.

Until the end of this study, 5 patients did not still experience disease progression and 30 were still survived. In patients who had their disease progressed, the median PFS was 8.3 months (95\% CI: 6.50-10.2), which was slightly less compared with WJTOG3405 (9.2 months), IFUM (9.7 months), NEJ002 (10.8 months), or IPASS (12 months) studies. ${ }^{9,12,14,15,20}$ In patients who died, the median OS was 16 months (95\% CI: 11.9-20.2). Again it was shorter compared with IPASS or IFUM study. ${ }^{9,20}$ This difference could be due to different facilities and ability to give optimum supportive care in our hospital.

The treatment response was assessed every 6 weeks until disease progression in the IPASS study. In this study, semisubjective response ( $\mathrm{QoL}$ ) was evaluated every month, whereas objective response was evaluated every 2 months. The IPASS study assessed the QoL using the Functional Assessment of Cancer Therapy-Lung (FACT-L) questionnaire where the score was 0 to 136 . Higher FACT-L scores denote better QoL. Trial Outcome Index (TOI) has a score between 0 and 84, in which higher scores indicate better QoL. Symptoms were assessed using an LCS score (score $0-28$, with higher scores showing fewer symptoms). ${ }^{9}$ In our study, the QoL was assessed using Eq. 5D because it is more practical with a score between 5 and 15 (lower scores indicate a better QoL).
During gefitinib therapy, two-thirds (43/63) of the patients experienced improved or stable QoL, whereas the rest (20/63) experienced a decrease in QoL. These results were consistent with other studies that showed improved QoL in patients receiving gefitinib compared with standard chemotherapy. According to Shao et al in Taiwan, initial Eq. 5D can be used to predict the time of treatment failure in NSCLC patients receiving gefitinib as first-line therapy. ${ }^{21}$ While using different tools to assess QoL (Care Notebook or FACT-L questionnaire), NEJ002 and IPASS studies also showed that QoL was maintained longer in patients receiving gefitinib compared with standard chemotherapy..$^{9,12,15}$

The efficacy of gefitinib shown in the IPASS study was accompanied with low incidence of alopecia, nausea, vomiting, neurotoxic symptoms, and myelosuppression compared with carboplatin-paclitaxel. ${ }^{9}$ The most common side effects found in the WJTOG3405 study were skin rash, followed by impaired liver function, dry skin, and diarrheaalmost the same as the NEJ002 study (skin rash and diarrhea)..$^{12,13,15}$ The most common side effects of gefitinib in our study were itchy skin rash and diarrhea. Impaired liver function in our study was found only in one patient. This result might be due to no routine evaluation of liver function tests in our study. No patients had interstitial lung disease in this study, compared with $2.6 \%$ of patients in the IPASS study. Nevertheless, the side effects occurred in this study did not lead to dose reduction or drug discontinuation.

To our knowledge, this study is the first to report the objective and subjective responses to gefitinib as first-line treatment in advanced EGFR-mutated NSCLC in Indonesia. This was a retrospective study in which all the data were retrieved from patients' medical record, so the limitation of this study was the difficulty to confirm dubious data from the medical records, especially in patients who have died. Sometimes patients cannot regularly come to the hospital to take the drugs during treatment, and the drugs were taken by the family. In that situation, the reported patient's complaint and body weight data were only obtained from the family representative who came to the hospital. Some of the Eq. $5 \mathrm{D}$ questionnaires were also filled using the informations from the family representative, and we can only rely on their observations. Another limitation was the reading of the CT scans by the different radiologist, so the interpretation of RECIST 1.1 might vary. To overcome this potential bias, we asked one senior radiologist to review all the CT scans data and interpretations. We only use these data for the calculation of PFS and OS estimation.

\section{Conclusion}

Gefitinib as first-line therapy provides a good objective response in EGFR-mutated NSCLC in Dr., Soetomo General Hospital, Surabaya, Indonesia, with median PFS of 8.3 months (95\% CI: 6.50-10.2) and median OS of 16 months (95\% CI: 11.9-20.2). QoL improved or remained stable in most patients. Gefitinib was generally well tolerated. The most common side effects were itchy skin 
rash and diarrhea that did not lead to dose reduction or drug discontinuation.

\section{Funding}

Laksmi Wulandari received financial and technical support from PT AstraZeneca Indonesia for this investigator-initiated research.

\section{Conflict of Interest}

Lakshmi Wulandari received honoraria from AstraZeneca, Roche, and Boehringer Ingelheim as a member of speaker bureau. Any other authors have no financial or personal relationships with people or organizations that could inappropriately influence our work.

\section{Note}

All authors contributed equally to this work.

\section{Acknowledgments}

The authors would like to thank PT, Astrazeneca, Indonesia, for financial and technical support for this investigator-initiated research study. They also thank Ms. Judith Owen, Ms. Hillary Davidson, Ms. Miranda Rachellina, and Ms. Roselini Ngiono for their thorough review and suggestion for study protocol, statistics, and Ms. Estini Mahendrarajah for manuscript review and language editing.

\section{References}

1 Silvestri GA and Jett J. Bronchogenic carcinoma. In: Mason RJ, ed. Murray and Nadel's Textbook of Respiratory Medicine. 4th ed. Philadelphia, PA: Elsevier Saunders; 2005: 1357-1382

2 Ettinger DS, Wood DE, Akerley W, et al; National comprehensive cancer network. Non-small cell lung cancer, version 6.2015. J Natl Compr Canc Netw 2015;13(5):515-524

3 American Cancer Society. Cancer Facts \& Figures 2016. Atlanta: American Cancer Society; 2016. Available at: http://www.m.cancer.org/research/cancerfactstatistics. Accessed May 24, 2018.

4 INFODATIN. Stop Kanker. Pusat Data Dan Informasi Kementerian Kesehatan RI; 2015. http://www.depkes.go.idinfodatin-kanker

5 Franklin WA, Noguchi M, Gonzales A. Molecular and cellular pathology of lung cancer. In: Pass HI, Carbone DP, Minna JD, et al, eds. Principles and Practice of Lung Cancer. 4th ed. Philadelphia, PA: Lippincott Williams and Wilkins; 2010: 287-324

6 Brambilla E, Travis WD, Colby TV, Corrin B, Shimosato Y. The new World Health Organization classification of lung tumours. Eur Respir J 2001;18(6):1059-1068

7 Litzky LA. The pathology of non-small-cell lung carcinoma. In: Grippi MA, Elias JA, Fishman AP, eds. Fishman's Pulmonary Disease and Disorders. 4th ed. McGraw-Hill; 2008:1831-1832

8 Detterbeck FC, Decker RH, Tanoue L, Lilenbaum RC. Non-small cell lung cancer. In: DeVita VT, Lawrence TS, Rosenberg SA, eds. Cancer: Principles \& Practice of Oncology. 10th ed. Philadelphia, PA: Wolters Kluwer Health/Lippincott Williams \& Wilkins;2011:1548-1670
9 Mok TS, Wu YL, Thongprasert S, et al. Gefitinib or carboplatin-paclitaxel in pulmonary adenocarcinoma. N Engl J Med 2009;361(10):947-957

10 Wulandari L. Epidermal growth factor receptor tyrosine kinase inhibitor: Terobosan baru dalam Terapi Kanker Paru. In: Proceeding Book of Pendidikan Kedokteran Berkelanjutan VIII Ilmu Penyakit Paru Bronchogenic Carcinoma: An Evidence Based Approach; 2006:10-20

11 Gridelli C, De Marinis F, Di Maio M, Cortinovis D, Cappuzzo F, Mok T. Gefitinib as first-line treatment for patients with advanced non-small-cell lung cancer with activating epidermal growth factor receptor mutation: review of the evidence. Lung Cancer 2011;71(3):249-257

12 Maemondo $\mathrm{M}$, Inoue $\mathrm{A}$, Kobayashi $\mathrm{K}$, et al; North-East Japan Study Group. Gefitinib or chemotherapy for non-small-cell lung cancer with mutated EGFR. N Engl J Med 2010;362(25):2380-2388

13 Kris MG, Natale RB, Herbst RS, et al. Efficacy of gefitinib, an inhibitor of the epidermal growth factor receptor tyrosine kinase, in symptomatic patients with non-small cell lung cancer: a randomized trial. JAMA 2003;290(16):2149-2158

14 Mitsudomi T, Morita S, Yatabe Y, et al; West Japan Oncology Group. Gefitinib versus cisplatin plus docetaxel in patients with non-small-cell lung cancer harbouring mutations of the epidermal growth factor receptor (WJTOG3405): an open label randomised phase 3 trial. Lancet Oncol 2010;11(2):121-128

15 Inoue $\mathrm{A}$, Kobayashi $\mathrm{K}$, Maemondo $\mathrm{M}$, et al; North-East Japan Study Group. Updated overall survival results from a randomized phase III trial comparing gefitinib with carboplatin-paclitaxel for chemo-naïve non-small cell lung cancer with sensitive EGFR gene mutations (NEJ002) Ann Oncol 2013;24(1):54-59

16 Paez JG, Jänne PA, Lee JC, et al. EGFR mutations in lung cancer: correlation with clinical response to gefitinib therapy. Science 2004;304(5676):1497-1500

17 Rosell R, Moran T, Queralt C, et al; Spanish Lung Cancer Group. Screening for epidermal growth factor receptor mutations in lung cancer. N Engl J Med 2009;361(10):958-967

18 Pao W, Miller V, Zakowski M, et al. EGF receptor gene mutations are common in lung cancers from "never smokers" and are associated with sensitivity of tumors to gefitinib and erlotinib. Proc Natl Acad Sci U S A 2004;101(36):13306-13311

19 Rahmawati D, Wulandari L. Respons Kemoterapi Dan Efek Samping Penggunaan Inhibitor Tirosine Kinase (Gefitinib) Pada Penderita Kanker Paru Bukan Sel Kecil (KPKBSK) Yang Menyandang Mutasi Gena Reseptor EGF di RSUD Dr. Soetomo Surabaya [Thesis]. Surabaya, Indonesia: University of Airlangga; 2015

20 Douillard JY, Ostoros G, Cobo M, et al. First-line gefitinib in Caucasian EGFR mutation-positive NSCLC patients: a phase-IV, open-label, single-arm study. Br J Cancer 2014;110(1):55-62

21 Shao Y, Lin Z, Hu F, et al. Quality of life in advanced non-small cell lung cancer patients receiving first-line gefitinib monotherapy. J Clin Oncol 2009;27:9614 